\title{
SELECTIVE METHYLATION OF RUTIN
}

\author{
V. S. Batyuk
}

Khimiya Prirodnykh Soedinenii, Vol. 6, No. 3, pp. 368-369, 1970

UDC 547.972

On methylation with dimethyl sulfate in an aqueous medium in the presence of alkali, the rate of methylation rises in the sequence $3>3^{\prime}>4^{\prime}>7$ [1]. By the selective methylation of rutin $\left(3,4,7,3^{\prime}, 4^{\prime}\right.$-pentahydroxyflavone $3-\mathrm{O}-\beta-\mathrm{D}$-glucopyranosyl- $(6-1)-\alpha-\mathrm{L}-$ rhamnopyranoside) with dimethyl sulfate in an aqueous solution of borax we

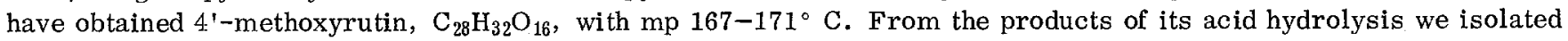

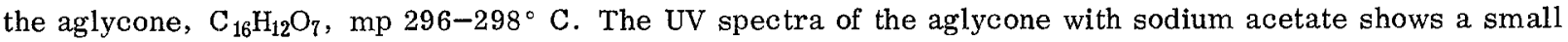
bathochromic shift of band I $(11 \mathrm{~m} \mu)$. Under these conditions, band II remains almost unchanged, which is characteristic for quercetin methylated in position 7 or $4^{\prime}$. Substance II is obviously methylated in position $4{ }^{\prime}$, since in an aqueous medium the methylation of flavonoids with dimethyl sulfate in position 7 is hindered [1].

By its physicochemical properties, UV spectra, and chromatographic behavior, the aglycone was identified as $3,5,7,3^{\prime}$-tetralhydroxy-4'-methoxyflavone.

\section{REFERENCE}

1. T. H. Simpson and J. L. Beton, J. Chem. Soc., 4065, 1954.

8 January 1970

Khar ${ }^{\dagger}$ kov Scientific-Research Chemical and Pharmaceutical Institute 